\title{
Non-contraceptive benefits of oral contraceptives
}

\author{
This article was published in the following Dove Press journal: \\ Open Access Journal of Contraception \\ 14 October 2011 \\ Number of times this article has been viewed
}

\author{
Marc Dhont \\ Department of Obstetrics and \\ Gynecology, Ghent University \\ Hospital, Ghent, Belgium
}

Correspondence: Marc Dhont Department of Obstetrics and Gynecology, Universitair Ziekenhuis, Gent, De Pintelaan 182, B-9000 Gent, Belgium

Tel +32 93323792

Fax +3293322162

Email marc.dhont@ugent.be
Abstract: The health benefits of the oral contraceptive (OC) pill are numerous and outweigh the risks of $\mathrm{OC}$ use. There are unintended but useful preventive side effects and potential therapeutic uses of OCs apart from contraception itself. Unequivocal evidence for the protective influence of combined OCs against ovarian and endometrial cancers, and colon cancer to a lesser extent, has been found. The pill also reduces the incidence of benign breast disease, functional ovarian cysts, pelvic inflammatory disease requiring hospitalization, ectopic pregnancy, and irondeficiency anemia. The pill can be used for the treatment of several gynecologic disorders such as dysmenorrhea, irregular or excessive bleeding, acne, hirsutism, and endometriosis-associated pain, whether prescribed solely to treat these symptoms or prescribed to treat them in addition to providing contraception. These health benefits are often underestimated, as they get too little attention from the mass media.

Keywords: the pill, estrogens, progestogens, safety, contraception

\section{Introduction}

Although the primary purpose of oral contraceptives (OCs) is to prevent unwanted conception, it is no wonder that the profound effect on the hormonal regulation of the menstrual cycle could entail some major effects on the female genital tract and the endocrine system. Estrogens, besides their anti-ovulatory effect, have a growth-promoting effect on the lining of the genital tract and the glandular breast tissue. Progestogens add to the contraceptive effect of estrogens by suppressing the ovulatory luteinizing hormone surge. They also thicken the cervical mucus, thereby hindering sperm migration into the upper genital tract, and they have an antiproliferative effect on the endometrium, making it less receptive for implantation. ${ }^{1}$ Both sex steroids have dose-related side effects. Progestogens do not bind exclusively to the progesterone receptor; they can also activate other steroid receptors to a certain degree. Estrogens promote the synthesis of several hepatic proteins and they have a well-established prothrombic effect. ${ }^{2}$ Although there is no doubt that estrogens increase the risk of thromboembolism two- to four-fold, fatal thromboembolism among young women is extremely rare ( $1 \%$ of cases), and this increased risk should be balanced against the five- to ten-fold increase in risk associated with normal pregnancy. On the other hand, besides the effective protection against unwanted conception, there are a number of beneficial effects. However, unintended but useful preventive side effects should not be equated with a potential therapeutic use of OCs. For instance, it is generally acknowledged that functional ovarian cysts are very rare in women taking combined oral contraceptives (COCs), but giving the 
pill to a woman who has developed a functional ovarian cyst will not hasten the disappearance of the cyst. ${ }^{3}$

The mechanisms of the non-contraceptive benefits of COCs can be directly related to the anti-ovulatory effect (eg, prevention of ovarian cancer), the antiproliferative effect of progestogens on the endometrium (eg, prevention of heavy menstrual bleeding, dysmenorrhea, and endometrial carcinoma), or the effects on the endocrine system (eg, the prevention of acne). Adding the non-contraceptive benefits to those of preventing unwanted pregnancy and the potential complications, COCs are associated with a significant reduction in the mortality rate. ${ }^{4}$

In this review both the non-contraceptive therapeutic benefits and the prophylactic benefits of COCs will be discussed.

\section{Preventive effects of COCs Ovarian cancer}

In 1995, three articles on the increased risk of thromboembolism for users of third-generation pills were published in the Lancet, inducing a temporary pill scare. Twelve years later, a January 2008 cover of the same journal stated: "Oral contraceptives have already prevented some 200,000 ovarian cancers and 100,000 deaths from ovarian cancer, and over the next few decades the number of cancers prevented will rise to at least 30,000 per year." ${ }^{\text {"5 }}$ This one statement neutralizes many of the warnings on the serious side effects of OCs and underscores the beneficial non-contraceptive effects of the pill. This publication was not the first to draw attention to the fact that users of COCs are less likely to develop ovarian cancer than nonusers. Since 1980, numerous case-control studies on the relationship between the use of COCs and the risk of ovarian cancer have been performed, and all concur that the risk in pill users is reduced by $30 \%-50 \% .^{6-10}$ This protective influence lasts for more than 10 years after cessation of pill use. Although the relative risk of developing ovarian cancer is reduced with increasing duration of OC intake, even short-term use of COCs for less than 6 months provides protection; ${ }^{11}$ however, this impact seems to be limited to those women who stop using COCs because of side effects. ${ }^{12}$ OC use may also reduce the risk of ovarian cancer in women with pathogenic mutations in the BRCA1 or BRCA2 gene. ${ }^{13}$ There is some controversy over whether the type of progestogens and the dose of progestogens and ethinyl estradiol matter. Lurie et $\mathrm{al}^{14}$ and Rosenblatt et al ${ }^{15}$ reported a somewhat lower risk reduction associated with low- vs high-potency OC formulations, but the differences were small and could have occurred by chance. In the study by
Lurie et al, ${ }^{14}$ an increased risk was limited to patients taking a high dose of norethindrone ( $10 \mathrm{mg}$ vs $0.5 \mathrm{mg}$ ); in the study by Rosenblatt et al, ${ }^{15}$ high potency was based solely on the estrogenic component, with no consideration of the progestogenic component. Another study, by Ness et al, ${ }^{16}$ suggested there were no differences in the risk reduction associated with COCs of varying estrogenic and progestogenic potencies. In contrast, a case-control study by Schildkraut et a $1{ }^{17}$ reported that the $\mathrm{COC}$ formulations with high progestogenic potency appear to be associated with a greater reduction in ovarian cancer risk than those with low progestogenic potency.

Based on epidemiological data, Fathalla ${ }^{18}$ formulated the hypothesis that "incessant" ovulation is a risk factor in ovarian neoplasia. Several epidemiological studies have indeed shown that the relative risk of ovarian cancer increases significantly with a higher number of lifetime ovulations. ${ }^{19-23}$ Although the precise mechanism of the relationship between the number of ovulations and the development of ovarian cancer is not known, the protective effect of COCs is mainly through reducing the number of ovulations.

\section{Endometrial cancer}

Mueck et al ${ }^{24}$ recently published a review of all studies of the relationship between endometrial cancer and hormonal contraception. More than 15 case-control studies and at least four large cohort studies demonstrated a decrease in the risk of endometrial cancer of about $50 \%$ if COCs had ever been used. In most of these studies, this protective influence persisted for more than 10,15 , or even 20 years after cessation of COC use. However, in the Royal College of General Practitioners' Oral Contraception Study, the protective impact of COCs was restricted to 5 years or less after cessation of pill use. ${ }^{25}$ An increasing protective influence with longer duration of COC use was found in most studies. The beneficial impact was independent of the composition of the COC (ie, dosage and type of progestogen, combined with ethinyl estradiol $30-50 \mathrm{mg} /$ day). COCs with higher progestogenic potency seem to be more effective.

The mechanism of protection against endometrial cancer is different from that against ovarian cancer. Most endometrial cancers $(70 \%-80 \%)$ are induced by chronic estrogenic stimulation. The progestogenic compound of COCs protects from estrogen-induced hyperplasia and changes in proliferative status.

\section{Colorectal cancer}

Several case-control and cohort studies have focused on the relationship between colon cancer and the use of COCs and 
a number of meta-analyses have been performed; however, the conclusion is not unanimous.

In the Nurses' Health Study, women who used OCs for 96 months or longer had a $40 \%$ lower risk of developing colorectal cancer (risk ratio [RR]: 0.60, 95\% confidence interval [CI]: $0.40-0.89 ; P$ for trend 0.02 ) than women who never used OCs. ${ }^{26}$ In a meta-analysis, the combined RR for colorectal cancer from eight case-control studies and four cohort studies for those who had ever used COCs was $0.82 .{ }^{27}$ The favorable effect of COC use on the risk of colon cancer was confirmed in a recent meta-analysis by Bosetti et al. ${ }^{28}$ The summary relative risk of colorectal cancer for those who had ever used COCs vs those who had never used COCs was 0.82 (95\% CI: 0.69-0.97) from eleven case-control studies, 0.81 (95\% CI: 0.75-0.89) from seven cohort studies, and 0.81 (95\% CI: 0.72-0.92) from all studies combined. The results were similar for colon and rectal cancer individually. For both colon and rectal cancer, there was no evident difference according to duration of the COC use. In contrast to these studies, Long et $\mathrm{al}^{29}$ found no risk reduction for distal large bowel cancer through use of OCs. These authors hypothesized that the lack of a protective effect seen in their study may be explained by modern-day formulations of OCs: previous studies showing a protective effect might have disproportionately contained women who used higher-dose estrogen formulations than those predominantly used today. Therefore, it is still unclear whether COCs effectively reduce, albeit moderately, the risk of bowel cancer.

\section{Functional ovarian cysts}

It has long been acknowledged that COCs greatly reduce the incidence of functional ovarian cysts. ${ }^{30}$ Originally this observation led to it being inferred that COCs could be used to treat functional ovarian cysts; however, randomized controlled trials as summarized in a recent review have shown that COCs do not hasten the resolution of functional ovarian cysts. ${ }^{3}$ There are two types of functional ovarian cysts: follicular and luteal. Follicular cysts arise from follicles that fail to rupture at the time of ovulation and which can continue to grow; they can reach a diameter of up to $5 \mathrm{~cm}$. After ovulation, the corpus luteum can be transformed into a mostly hemorrhagic corpus luteum cyst. In both cases, acute complications due to torsion or rupture can occur. Because COCs suppress ovulation, it is evident that the occurrence of luteal cysts will be prevented through COC use. The degree of prevention of follicular cysts will depend on the type of COC: high-dose pills will be more effective than low-dose pills. Because follicles start growing in the pill-free interval, the continuous use of COCs will also be more effective in preventing follicular cysts than the usual 21-/28-day regimen.

\section{Endometriosis}

Although the precise etiopathology of endometriosis is unknown, reflux of endometrial cells at the time of menstruation is generally considered to be the initiating event. Extra-uterine implantation and growth of endometrial cells is further promoted by the cyclic production of estrogens. COCs could prevent the initiation or extension of endometriosis by two mechanisms: the volume of menstrual flow is reduced and progestogens, either directly or by their anti-estrogenic effect, prevent implantation and growth of endometrial cells. A number of case-control and cohort studies have shown that the risk of endometriosis is reduced in pill users. ${ }^{31}$ However, studies on the favorable effect of COCs on the risk of endometriosis may be somewhat biased: the suppression of symptoms, including potential subfertility, frequently postpones diagnostic evaluation. The question of whether COCs are instrumental in the primary prevention of endometriosis remains to be answered.

\section{Uterine leiomyomas}

The occurrence of uterine leiomyomas or fibroids is determined by genetic factors and exposure to estrogens. Therefore, reproductive events impact on the risk of developing fibroids. For instance, there is an inverse relationship between the incidence of fibroids and the number of term pregnancies; an inverse relationship can also be found between the incidence of fibroids and smoking. Due to the anti-estrogenic activity of progestogens, COCs could have a protective effect on the development of fibroids. Indeed, the Oxford Family Planning Association found that the risk of fibroids was reduced by about $31 \%$ in women who had used OCs for 10 years and that it also decreased consistently with an increasing duration of OC use. ${ }^{32}$

\section{Benign breast disease}

Benign breast disease is a collective term referring to a number of benign breast conditions such as fibrocystic breast disease, fibroadenoma, and undefined breast lumps. Various risk factors for benign breast disease have been assessed by analysis of data obtained from a multicenter cohort study of contraceptive use among women in the United Kingdom. ${ }^{33}$ An inverse association was found between use of OCs and the risk of fibroadenoma, chronic cystic disease, and breast lumps. Current users of the pill had the lowest risk, particularly when the use was for an extended period. In contrast, 
past users demonstrated no reduction in risk. Because this study comprised mainly women on COCs containing estrogen of $50 \mu \mathrm{g}$ or more, the analysis was recently updated to include a much larger number of cases and also a substantial number of women taking low-dose COCs. ${ }^{34}$ It was concluded that all types of COCs appear to reduce the incidence of benign breast disease. All observational studies on the relationship between COC use and diseases are subject to different kinds of biases (eg, prescription and selection bias) and confounding factors, and therefore conclusions on presumed benefits of COCs should be approached with caution. However, the fact that a protective effect was also reported in a large prospective cohort study confirms the contention that COCs indeed reduce the incidence of benign breast disease. ${ }^{35}$

\section{Iron-deficiency anemia}

It is well known that COCs reduce menstrual blood loss by about $50 \%$, both in quantity and in duration. ${ }^{36,37}$ This applies not only to normally menstruating women but also to women suffering from heavy menstrual blood loss. About 10\% of menstruating women suffer from heavy menstrual bleeding (defined as a menstrual blood loss of more than $80 \mathrm{~mL}$ ). It is particularly in those women that COCs are able to prevent iron-deficiency anemia. In normally menstruating women, no difference was observed in the biomarkers of iron deficiency between users and nonusers of COCs. ${ }^{38}$

\section{Pelvic inflammatory disease}

Earlier studies have shown that COCs may protect against acute episodes of pelvic inflammatory disease. ${ }^{39}$ However, a meta-analysis of prospective and case-control studies found an odds ratio (OR) of 1.93 (95\% CI: 1.77-2.11) for the risk of chlamydial infection for COC users. ${ }^{40}$ In a study among commercial sex workers in Mombasa, Kenya, the use of hormonal contraception by HIV-1-infected women was associated with an increased risk of cervicitis and cervical Chlamydia infection. ${ }^{41}$ It may be concluded that COCs enhance the risk of acquiring sexually transmitted infections, presumably by their effect on the cervical epithelium. These findings do not necessarily contradict previous reports on the reduced risk of acute pelvic inflammatory disease, but they indicate that COCs are at least ineffective in preventing the transmission of venereal diseases.

\section{Rheumatoid arthritis}

There have been many studies on the role of COCs in rheumatoid arthritis (RA). ${ }^{42-46}$ The majority of studies have found that past or current use of COCs has a protective effect against
RA development. ${ }^{47}$ In a recent case-control study, Berglin et $\mathrm{al}^{48}$ reported a decreased risk for development of RA in women who had been using COCs for 7 years or more (OR: 0.37; 95\% CI: 0.15-0.93). In the Norfolk Arthritis Register, which is a primary care-based cohort of patients with recentonset inflammatory polyarthritis, it was found that COC users have a better functional outcome than nonusers. COC use at baseline and before onset of symptoms appeared to have the most consistent benefit. ${ }^{49}$

\section{Noncontraceptive therapeutic indications for COCs Heavy menstrual bleeding}

COCs are associated with a decreased menstrual flow by limiting endometrial proliferation. Although COCs are widely used as a first-line treatment for heavy menstrual bleeding, it is remarkable that until very recently there was a lack of published randomized trial data to definitely prove the efficacy of COCs for this treatment. One small nonrandomized crossover trial $(n=45)$ showed that COCs were effective in modulating blood loss, on average providing a $40 \%-50 \%$ decrease, along with a decrease in the occurrence of dysmenorrhea. ${ }^{50}$ Because of the lack of solid proof of efficacy, Farquhar and Brown $^{51}$ concluded in a recent Cochrane review that there were not enough trial data to recommend COCs for treatment of abnormal uterine bleeding. It should be remembered that lack of evidence does not necessarily mean that COCs cannot be effective in reducing blood loss in women with heavy menstrual bleeding. Several decades of clinical experience attests to the place of COCs in the treatment of heavy menstrual bleeding. Recently, two randomized trials of an OC containing estradiol valerate and dienogest provided solid proof of the efficacy of COCs for this treatment. ${ }^{52,53}$ The reduction of blood loss in the study group varied from $60 \%$ to $70 \%$ compared with the placebo group. ${ }^{52,53}$ Less-frequent menses or amenorrhea can be achieved with extended estrogen-progestogen COC regimens; however, there are no studies to prove that this mode of administration is superior to the cyclic use of COCs for treating heavy menstrual bleeding.

\section{Dysmenorrhea}

Dysmenorrhea or painful menstruation is associated with ovulatory cycles. Headaches, nausea, and vomiting can be accompanying symptoms. With the withdrawal of progesterone and estradiol at the end of the ovulatory cycle, a cascade of endometrial events begins, including the production and release of prostaglandins, which are thought to be the main factor in painful uterine contractions. As COCs suppress 
ovulation and reduce the proliferation of the endometrium (and therefore also reduce the production of prostaglandins), they could be effective in reducing the symptoms of dysmenorrhea. A recent Cochrane review concluded that preparations of COCs with doses less than $35 \mu \mathrm{g}$ were effective and should be the preparation of choice. ${ }^{54}$ Two recent randomized trials showed that COCs are effective for the treatment of primary dysmenorrhea ${ }^{55}$ as well as for secondary dysmenorrhea due to endometriosis. ${ }^{56}$ Even better results can be obtained by COCs used in a continuous fashion. Headaches, genital irritation, tiredness, bloating, and menstrual pain were significantly reduced in the extended cycles. ${ }^{57}$

\section{Premenstrual syndrome}

"Premenstrual syndrome (PMS) is a psychological and somatic disorder of unknown etiology. The symptoms of PMS regularly occur during the luteal phase of the menstrual cycle and resolve by the end of menstruation." ${ }^{58}$ It is estimated that $5 \%$ of all women of fertile age suffer from severe PMS. ${ }^{59}$ COCs prevent ovulation and should be effective for the treatment of PMS. However, evidence from the limited studies available does not support the efficacy of $\mathrm{OC}$ agents containing progestogens derived from 19-nortestosterone. ${ }^{60}$ The combination of estrogen and progestogen may produce symptoms similar to PMS, such as water retention and irritability. The introduction of an OC pill containing low-dose ethinyl estradiol and a new progestogen, drospirenone, has offered clinical efficacy for PMS. ${ }^{61}$ Drospirenone is a spironolactone derivative with antimineralocorticoid and anti-androgenic activity. Drospirenone's anti-androgenic activity makes it also effective in the reduction of acne and seborrhea. The antimineralocorticoid activity helps to reduce some of the bothersome symptoms (such as swelling) associated with the premenstrual phase of the menstrual cycle. Therefore, this pill has the potential to improve women's quality of life. There is some evidence that triphasic OCs are more effective for some of the symptoms of PMS.${ }^{62}$ In a study by Graham and Sherwin, ${ }^{63}$ premenstrual breast pain and bloating were found to be significantly reduced with a triphasic OC; however, there were no beneficial effects for any of the mood symptoms. Continuous oral contraception provides greater suppression of the ovary and endometrium and it avoids the cyclic interruption of the hormonal exposure that may trigger some symptoms associated with PMS. It has been shown that this mode of oral contraception is associated with improved patient symptomatology..$^{57,64}$

\section{Endometriosis}

Medical therapy is an important alternative or complement to surgery for symptomatic endometriosis. Because endometriosis is an estrogen-dependent disease, medical treatments are based on their systemic or local anti-estrogenic effects. Both progestogens and COCs are as effective as more sophisticated and more expensive drugs such as gonadotropin-releasing hormone analogs or aromatase inhibitors. ${ }^{65}$ "COCs also reduce the rate of postoperative endometrioma recurrence and should now be considered an essential part of long-term therapeutic strategies in order to limit further damage to future fertility" ${ }^{65}$

\section{Acne}

Acne is a common skin disorder that occurs in both sexes and particularly affects teenagers (when androgens start stimulating the sebaceous glands to increase production of sebum). Although the etiopathology of acne is complex, reduction of androgen production or antagonizing their effect on the sebaceous glands is one of the pillars of a successful treatment. COCs reduce the steroid production by the ovaries: the estrogenic component increases the production of sex hormone-binding globulin whereas the progestogenic component can interact to varying degrees with the androgen receptors. Newer synthetic progestogens, such as the thirdgeneration gonanes desogestrel and norgestimate, have less activity at the androgen receptor and more specificity for the progestogen receptor, and therefore the androgenic effects are minimized. "Cyproterone acetate is a synthetic derivative of 17-hydroxyprogesterone; it is approved in Europe for the treatment of acne, hirsutism, and alopecia but it is not available in the United States" ${ }^{66}$ Cyproterone acetate may be used as a sole agent or in combination with ethinyl estradiol. In the latter case it is prescribed as an OC particularly for the treatment of acne (Diane- $35^{\circledR}$ ). Drospirenone is a relatively new fourth-generation progestogen that partially blocks endogenous androgens from binding the androgen receptor. A recent Cochrane review provided a comprehensive assessment of the efficacy of COCs for the treatment of acne in women. ${ }^{67}$ It was found that all types of COCs were effective for the treatment of acne and that in this respect only subtle differences existed between COCs with different types of progestogens. This proves that the effect of COCs on the androgen level is the most important factor.

\section{Perimenopausal symptoms}

The years of fluctuating ovarian function leading up to the final cessation of menstruation are termed the 
perimenopause. This commonly lasts between 2 to 3 years, usually in a woman's late forties or early fifties. During the perimenopause, menstrual bleeding typically becomes irregular and menopausal symptoms may be experienced. Although fertility is low, most perimenopausal women are anxious to avoid any risk of pregnancy. Vasomotor symptoms are experienced by up to $80 \%$ of women during the menopausal transition. Hot flushes, night sweats, and palpitations may significantly affect daily life and interfere with sleep, reducing quality of life for perimenopausal women. Estrogen-containing hormonal regimens offer effective treatment for vasomotor symptoms and remain the treatment of choice if symptoms are severe. For perimenopausal women with irregular, anovulatory cycles, COCs regulate the menstrual bleeding pattern, reducing both bleeding and pain. In healthy older women, these very significant menstrual benefits may well outweigh any small risks associated with COC use. These risks need to be evaluated in the context of each woman's individual risk profile and weighed against the potential benefits: effective contraception, predictable bleeding patterns that are less heavy and less painful, reduction in vasomotor symptoms, maintenance of bone mineral density, and protection against ovarian and endometrial cancer. ${ }^{68}$

\section{Conclusion}

Not only are OCs one of the most effective methods of contraception but also they confer a number of health benefits, either by prevention of some diseases or through their use in the treatment of some gynecological disorders or discomfort related to the menstrual cycle. Besides a proven substantial reduction in the risk of ovarian and endometrial cancer, preventive effects on benign breast disease, endometriosis, fibroids, RA, and colon cancer are less pronounced, and in certain cases not unequivocally proven. Since the birth of the pill some 50 years ago, numerous changes in dosage and composition have been introduced with the general aim, apart from some commercial motives, to reduce side effects without affecting the contraceptive efficacy. The estrogen and progestogen dosage has been reduced, new progestogens have been added, alternative modes (24-day cycles, extended use of COCs) and routes of administration (transdermal, vaginal) are now offered, and, more recently, ethinyl estradiol has been replaced by natural estradiol combined with a selective progestogenic compound. Randomized studies on all these new formulations have mainly focused on contraceptive efficacy, cycle control, and biochemical variables as a substitute for potential adverse health effects.
Imitation of the natural cycle is sometimes put forward as a positive argument in the promotion of new brands of OCs. However, the restoration of a menstrual cycle is not necessarily associated with long-term beneficial side effects. Repeated and year-long menstruation is a rather recent phenomenon in human history; in fact, it is associated with the increase in some diseases such as ovarian, endometrial, and colon cancer. ${ }^{69} \mathrm{New}$ formulations of OCs should also be evaluated with respect to their beneficial noncontraceptive side effects.

\section{Disclosure}

The author reports no conflicts of interest in this work.

\section{References}

1. Rivera R, Yacobson I, Grimes D. The mechanism of action of hormonal contraceptives and intrauterine contraceptive devices. Am J Obstet Gynecol. 1999;181(5 Pt 1):1263-1269.

2. Martinez F, Avecilla A. Combined hormonal contraception and venous thromboembolism. Eur J Contracept Reprod Health Care. 2007;12(2):97-106.

3. Grimes DA, Jones LB, Lopez LM, Schulz KF. Oral contraceptives for functional ovarian cysts. Cochrane Database Syst Rev. 2009;2:CD006134.

4. Hannaford PC, Iversen L, Macfarlane TV, Elliott AM, Angus V, Lee AJ. Mortality among contraceptive pill users: cohort evidence from Royal College of General Practitioners' Oral Contraception Study. BMJ. 2010; 340:c927.

5. Beral V, Doll R, Hermon C, Peto R, Reeves G; for Collaborative Group on Epidemiological Studies of Ovarian Cancer. Ovarian cancer and oral contraceptives: collaborative reanalysis of data from 45 epidemiological studies including 23,257 women with ovarian cancer and 87,303 controls. Lancet. 2008;371(9609):303-314.

6. The Centers for Disease Control Cancer and Steroid Hormone Study. Oral contraceptive use and the risk of ovarian cancer. JAMA. 1983;249(12):1596-1599.

7. La Vecchia C, Franceschi S, Decarli A. Oral contraceptive use and the risk of epithelial ovarian cancer. Br J Cancer. 1984;50(1):31-34.

8. Cancer and Steroid Hormone Study of the Centers for Disease Control and the National Institute of Child Health and Human Development. The reduction in risk of ovarian cancer associated with oral-contraceptive use. $N$ Engl J Med. 1987;316(11):650-655.

9. WHO Collaborative Study of Neoplasia and Steroid Contraceptives. Epithelial ovarian cancer and combined oral contraceptives. Int J Epidemiol. 1989;18(3):538-545.

10. Rosenberg L, Palmer JR, Zauber AG, et al. A case-control study of oral contraceptive use and invasive epithelial ovarian cancer. Am JEpidemiol. 1994;139(7):654-661.

11. Gross TP, Schlesselman JJ, Stadel BV, Yu W, Lee NC. The risk of epithelial ovarian cancer in short-term users of oral contraceptives. Am J Epidemiol. 1992;136(1):46-53.

12. Greer JB, Modugno F, Allen GO, Ness RB. Short-term oral contraceptive use and the risk of epithelial ovarian cancer. Am J Epidemiol. 2005;162(1):66-72.

13. Narod SA, Risch H, Moslehi R, et al. Oral contraceptives and the risk of hereditary ovarian cancer: Hereditary Ovarian Cancer Clinical Study Group. N Engl J Med. 1998;339(7):424-428.

14. Lurie G, Thompson P, McDuffie KE, Carney ME, Terada KY, Goodman MT. Association of estrogen and progestin potency of oral contraceptives with ovarian carcinoma risk. Obstet Gynecol. 2007;109(3):597-607. 
15. Rosenblatt KA, Thomas DB, Noonan EA. High-dose and low-dose combined oral contraceptives: protection against epithelial ovarian cancer and the length of the protective effect; the WHO Collaborative Study of Neoplasia and Steroid Contraceptives. Eur J Cancer. 1992;28A(11):1872-1876.

16. Ness RB, Grisso JA, Klapper J, et al. Risk of ovarian cancer in relation to estrogen and progestin dose and use characteristics of oral contraceptives: SHARE Study Group; steroid hormones and reproductions. Am J Epidemiol. 2000;152(3):233-241.

17. Schildkraut JM, Calingaert B, Marchbanks PA, Moorman PG, Rodriguez GC. Impact of progestin and estrogen potency in oral contraceptives on ovarian cancer risk. J Natl Cancer Inst. 2002;94(1):32-38.

18. Fathalla MF. Incessant ovulation: a factor in ovarian neoplasia? Lancet. 1971;2(7716):163.

19. Hildreth NG, Kelsey JL, LiVolsi VA, et al. An epidemiologic study of epithelial carcinoma of the ovary. Am J Epidemiol. 1981;114(3):398-405.

20. La Vecchia C, Franceschi S, Gallus G, Decarli A, Liberati A, Tognoni G. Incessant ovulation and ovarian cancer: a critical approach. Int J Epidemiol. 1983;12(2):161-164.

21. Risch HA, Weiss NS, Lyon JL, Daling JR, Liff JM. Events of reproductive life and the incidence of epithelial ovarian cancer. Am J Epidemiol. 1983;117(2):128-139.

22. Wu ML, Whittemore AS, Paffenbarger RS Jr, et al. Personal and environmental characteristics related to epithelial ovarian cancer. I Reproductive and menstrual events and oral contraceptive use. Am J Epidemiol. 1988;128(6):1216-1227.

23. Purdy DM, Bain CJ, Siskind V, Webb P, Green AC. Ovulation and risk of epithelial ovarian cancer. Int J Cancer. 2003;104(2):228-232.

24. Mueck AO, Seeger H, Rabe T. Hormonal contraception and risk of endometrial cancer: a systematic review. Endocr Relat Cancer. 2010;17(4):R263-R271.

25. Hannaford PC, Selvaraj S, Elliott AM, Angus V, Iversen L, Lee AJ. Cancer risk among users of oral contraceptives: cohort data from the Royal College of General Practitioner's oral contraception study. BMJ 2007;335(7621):651.

26. Martinez EM, Grodstein F, Giovannucci E, et al. A prospective study of reproductive factors, oral contraceptive use, and risk of colorectal cancer. Cancer Epidemiol Biomarkers Prev. 1997;6(1):1-5.

27. Fernandez E, La Vecchia C, Balducci A, Chatenoud L, Franceschi S, Negri E. Oral contraceptives and colorectal cancer risk: a meta-analysis. Br J Cancer. 2001;84(5):722-727.

28. Bosetti C, Bravi F, Negri E, La Vecchia C. Oral contraceptives and colorectal cancer risk: a systematic review and meta-analysis. Hum Reprod Update. 2009;15(5):489-498.

29. Long MD, Martin CF, Galanko JA, Sandler RS. Hormone replacement therapy, oral contraceptive use and distal large bowel cancer: a population-based case-control study. Am J Gastroenterol. 2010; 105(8):1843-1850.

30. Ory HW. The noncontraceptive health benefits from oral contraceptive use. Fam Plann Perspect. 1982;14(4):182-184.

31. Vercellini P, Eskenazi B, Consonni D, et al. Oral contraceptives and risk of endometriosis: a systematic review and meta-analysis. Hum Reprod Update. 2011;17(2):159-170.

32. Ross RK, Pike MC, Vessey MP, Bull D, Yeates D, Casagrande JT. Risk factors for uterine fibroids: reduced risk associated with oral contraceptives. Br Med J (Clin Res Ed). 1986;293(6543):359-362.

33. Brinton LA, Vessey MP, Flavel R, Yeates D. Risk factors for benign breast disease. Am J Epidemiol. 1981;113(3):203-214.

34. Vessey M, Yeates D. Oral contraceptives and benign breast disease: an update of findings in a large cohort study. Contraception. 2007;76(6): $418-424$

35. Rohan TE, Miller AB. A cohort study of oral contraceptive use and risk of benign breast disease. Int J Cancer. 1999;82(2):191-196.

36. Nilsson L, Sölvell L. Clinical studies on oral contraceptives: a randomized, doubleblind, crossover study of 4 different preparations (Anovlar mite, Lyndiol mite, Ovulen, and Volidan). Acta Obstet Gynecol Scand. 1967;46(8 Suppl 8):1-31.
37. Larsson G, Milsom I, Lindstedt G, Rybo G. The influence of a low-dose combined oral contraceptive on menstrual blood loss and iron status. Contraception. 1992;46(4):327-334.

38. Casabellata G, Di Santolo M, Banfi G, Stel G, Gonano F, Cauci S. Evaluation of iron deficiency in young women in relation to oral contraceptive use. Contraception. 2007;76(3):200-207.

39. Rubin GL, Ory HW, Layde PM. Oral contraceptives and pelvic inflammatory disease. Am J Obstet Gynecol. 1982;144(6):630-635.

40. Cottingham J, Hunter D. Chlamydia trachomatis and oral contraceptive use: a quantitative review. Genitourin Med. 1992;68(4):209-216.

41. Baeten JM, Nyange PM, Richardson BA, et al. Hormonal contraception and risk of sexually transmitted disease acquisition: results from a prospective study. Am J Obstet Gynecol. 2001;185(2):380-385.

42. Royal College of General Practitioners' Oral Contraception Study. Reduction in incidence of rheumatoid arthritis associated with oral contraceptives. Lancet. 1978;1(8064):569-571.

43. Vandenbroucke JP, Valkenburg HA, Boersma JW, et al. Oral contraceptives and rheumatoid arthritis: further evidence for a preventive effect. Lancet. 1982;2(8303):839-842.

44. Vandenbroucke JP, Witteman JC, Valkenburg HA, et al. Noncontraceptive hormones and rheumatoid arthritis in perimenopausal women. JAMA. 1986;255(10):1299-1303.

45. Hazes JM, Dijkmans BAC, Vandenbroucke JP, de Vries RRP, Cats A. The preventive effect of oral contraceptives on the incidence of rheumatoid arthritis. Clin Exp Rheumatol. 1987;5(Suppl 2):27.

46. Doran MF, Crowson CS, O'Fallon WM, Gabriel SE. The effect of oral contraceptives and estrogen replacement therapy on the risk of rheumatoid arthritis: a population based study. J Rheumatol. 2004;31(2):207-213.

47. Pikwer M, Bergström U, Nilsson JA, Jacobsson L, Berglund G, Turesson C. Breast feeding, but not use of oral contraceptives, is associated with a reduced risk of rheumatoid arthritis. Ann Rheum Dis. 2009;68(4):526-530.

48. Berglin E, Kokkonen H, Einarsdottir E, Agren A, Rantapää Dahlqvist $S$. Influence of female hormonal factors, in relation to autoantibodies and genetic markers, on the development of rheumatoid arthritis in northern Sweden: a case-control study. Scand J Rheumatol. 2010;39(6):454-460.

49. Camacho EM, Lunt M, Farragher TM, Verstappen SM, Bunn DK, Symmons DP. The relationship between oral contraceptive use and functional outcome in women with recent-onset inflammatory polyarthritis: results from the Norfolk Arthritis Register (NOAR). Arthritis Rheum. 2011;63(8):2183-2191.

50. Fraser IS, McCarron G. Randomized trial of 2 hormonal and 2 prostaglandin-inhibiting agents in women with a complaint of menorrhagia. Aust N Z J Obstet Gynaecol. 1991;31(1):66-70.

51. Farquhar C, Brown J. Oral contraceptive pill for heavy menstrual bleeding. Cochrane Database Syst Rev. 2009;4:CD000154.

52. Jensen JT, Parke S, Mellinger U, Machlitt A, Fraser IS. Effective treatment of heavy menstrual bleeding with estradiol valerate and dienogest: a randomized controlled trial. Obstet Gynecol. 2011;117(4): $777-787$.

53. Fraser IS, Römer T, Parke S, et al. Effective treatment of heavy and/ or prolonged menstrual bleeding with an oral contraceptive containing estradiol valerate and dienogest: a randomized, double-blind Phase III trial. Hum Reprod. Epub July 21, 2011.

54. Wong CL, Farquhar C, Roberts H, Proctor M. Oral contraceptive pill for primary dysmenorrhoea. Cochrane Database Syst Rev. 2009;4:CD002120.

55. Harada T, Momoeda M, Terakawa N, Taketani Y, Hoshiai H. Evaluation of a low-dose oral contraceptive pill for primary dysmenorrhea: a placebo-controlled, double-blind, randomized trial. Fertil Steril. 2011;95(6):1928-1931.

56. Harada T, Momoeda M, Taketani Y, Hoshiai H, Terakawa N. Low-dose oral contraceptive pill for dysmenorrhea associated with endometriosis: a placebo-controlled, double-blind, randomized trial. Fertil Steril. 2008;90(5):1583-1588. 
57. Edelman A, Gallo MF, Jensen JT, Nichols MD, Schulz KF, Grimes DA. Continuous or extended cycle vs cyclic use of combined hormonal contraceptives for contraception. Cochrane Database Syst Rev. 2005;3: CD004695.

58. Usman SB, Indusekhar R, O’Brien S. Hormonal management of premenstrual syndrome. Best Pract Res Clin Obstet Gynaecol. 2008;22(2): 251-260.

59. Yonkers KA, O’Brien PM, Eriksson E. Premenstrual syndrome. Lancet. 2008;371(9619):1200-1210.

60. Freeman EW, Kroll R, Rapkin A, et al. Evaluation of a unique oral contraceptive in the treatment of premenstrual dysphoric disorder. J Womens Health Gend Based Med. 2001;10(6):561-569.

61. Dickerson V. Quality of life issues: potential role for an oral contraceptive containing ethinyl estradiol and drospirenone. J Reprod Med. 2002;47(11 Suppl):985-993.

62. Ross C, Coleman G, Stojanovska C. Prospectively reported symptom change across the menstrual cycle in users and non-users of oral contraceptives. J Psychosom Obstet Gynecol. 2003;24(1):15-29.

63. Graham CA, Sherwin BB. A prospective treatment study of premenstrual symptoms using a triphasic oral contraceptive. J Psychosom Res. 1992;36(3):257-266.
64. Legro RS, Pauli JG, Kunselman AR, et al. Effects of continuous versus cyclical oral contraception: a randomized controlled trial. J Clin Endocrinol Metab. 2008;93(2):420-429.

65. Vercellini P, Crosignani P, Somigliana E, Viganò P, Frattaruolo MP, Fedele L. "Waiting for Godot": a commonsense approach to the medical treatment of endometriosis. Hum Reprod. 2011;26(1):3-13.

66. Salvaggio HL, Zaenglein AL. Examining the use of oral contraceptives in the management of acne. Int J Womens Health. 2010;2:69-76.

67. Arowojolu AO, Gallo MF, Lopez LM, Grimes DA, Garner SE. Combined oral contraceptive pills for treatment of acne. Cochrane Database Syst Rev. 2009;3:CD004425.

68. Kaunitz AM. Oral contraceptive use in perimenopause. Am J Obstet Gynecol. 2001;185(2 Suppl):S32-S37.

69. Zervoudakis A, Strickler HD, Park Y, et al. Reproductive history and risk of colorectal cancer in postmenopausal women. J Natl Cancer Inst. 2011;103(10):826-834.
Open Access Journal of Contraception

\section{Publish your work in this journal}

Open Access Journal of Contraception is an international, peerreviewed, open access, online journal, publishing original research, reports, reviews and commentaries on all areas of contraception. In addition to clinical research, demographics and health-related aspects, the journal welcomes new findings in animal and preclinical studies

\section{Dovepress}

relating to understanding the biological mechanisms and practical development of new contraceptive agents. The manuscript management system is completely online and includes a very quick and fair peer-review system. Visit http://www.dovepress.com/testimonials.php to read real quotes from published authors. 